\title{
Bilateral popliteal aneurysms complicating adult polycystic kidney disease in a patient with a marfanoid habitus
}

\author{
W Al-Hakim, D J A Goldsmith
}

Postgrad Med J 2003;79:474-475

A man born in 1944 presented with an episode of macroscopic haematuria during a urinary tract infection in 1988. $\mathrm{He}$ was unusually tall at 2 metres. An intravenous pyelogram and an abdominal ultrasound disclosed the presence of bilaterally enlarged polycystic kidneys and a polycystic liver. There was a family history of renal disease. Plasma creatinine $(180 \mathrm{\mu mol} / \mathrm{I})$ and blood pressure $(150 / 100 \mathrm{~mm} \mathrm{Hg})$ were both raised. Despite good blood pressure control his renal function declined progressively and he started renal dialysis treatment in 1995. He received a renal allograft in 1996

In 1994 he had noticed a painful swelling behind his left knee. Computed tomography with contrast showed a large popliteal aneurysm. This was replaced with a vein graft. The right popliteal artery showed milder changes, and this was repaired in 1999.

Popliteal aneurysms develop most often in older vasculopaths with multiple risk factors; connective tissue disorders have rarely been associated with their presence in younger patients. Polycystic kidney disease has been associated with several aneurysms, most notably cerebral, but not popliteal. The patient's marfanoid habitus also may have played a part. This case emphasises the mixed aetiology of popliteal aneurysms.

A man born in 1944 presented with an episode of macroscopic haematuria during a urinary tract infection in 1988. An intravenous pyelogram and an abdominal ultrasound disclosed the presence of bilaterally enlarged polycystic kidneys and a polycystic liver. He was referred for a renal opinion.

There was a family history of renal disease and unusual tallness on his father's side. The patient was 2 metres tall, his father was 1.96 metres tall, and his son was 1.93 metres tall. His father had died in his 40s from hypertensive heart failure and was shown to have suffered from polycystic kidney disease (not diagnosed during life). There was no family history of note on the maternal side. At his presentation the index patient's plasma creatinine was raised at $180 \mu \mathrm{mol} / \mathrm{l}$, as was his blood pressure (150/100 mm Hg). Despite good blood pressure control his renal function declined progressively and he started renal dialysis treatment in 1995 . He received a renal allograft (anastomosed onto a normal internal iliac artery bearing no atherosclerosis) in 1996 which functions well to this day.

In 1994 he had noticed a painful swelling behind his left knee, with no history of trauma (he was a librarian with a sedentary lifestyle). A computed tomogram with contrast showed a large $(5 \mathrm{~cm})$ popliteal aneurysm (see fig l). This was replaced with a vein graft. The right popliteal artery showed milder changes which slowly progressed, and this was

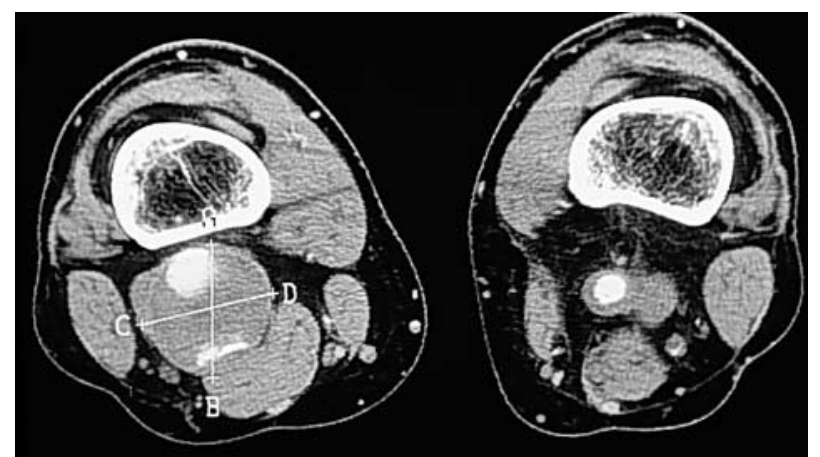

Figure 1 Computed tomogram of both legs at the level of the popliteal fossa showing bilateral popliteal aneurysms. Distance between $C$ and $D$ is $5 \mathrm{~cm}$.

repaired in 1999. He has no vascular symptoms. His abdominal aorta was of normal dimensions with no calcification on computed tomography. Ultrasonic angiology of his iliac and femoral arteries did not reveal atherosclerosis.

Systematic review revealed a man of unusual height, with long, slender fingers, a high arched palate, and inguinal hernias. He did not have joint laxity, his hand span was 1.95 metres (that is, just less than his height), and he had no pectus excavatum. An echocardiogram showed a normal left ventricle, aortic root, and aortic valve.

\section{DISCUSSION}

Arterial aneurysms have diverse aetiologies. Most commonly aneurysmal dilatation is a feature of advanced atherosclerosis seen in the lower aorta. However, inflammatory aneurysms are well described if rarer. ${ }^{1}$ Connective tissue disorders such as Ehlers-Danlos syndrome, neurofibromatosis type-1, and Marfan's syndrome have also been associated with aneurysms, often in children or younger adults..$^{2-4}$ In idiopathic aneurysms the role of matrix metalloproteinases and their tissue inhibitors in the aetiology of vascular connective tissue destruction is increasingly appreciated.

Popliteal aneurysms account for $70 \%$ of peripheral arterial aneurysms and, if untreated, pose a serious threat to the affected limb. Debate continues about the best form of treatment especially for asymptomatic lesions. ${ }^{6}$ The aetiology is typically atherosclerotic, with most patients aged over 50 and showing several classical vascular risk factors. ${ }^{7}$ Rarer causes include mycotic and traumatic complications as well as connective tissue disorders. In our case the patient did not have evidence of atherosclerosis elsewhere, in particular in two sites very prone to this disease: abdominal aorta (absence of calcification) and internal iliac artery (examined directly at transplantation).

Autosomal polycystic kidney disease (ADPKD) is the commonest inherited renal condition and is responsible for end 
stage renal disease in about $10 \%$ of patients on dialysis programmes. ${ }^{8}$ Vascular abnormalities have been associated with this diagnosis - as polycystin is known to be expressed by human vascular smooth muscle, ${ }^{9}$ particularly saccular intracranial aneurysms-indeed in some kindreds there is a clear history of sudden death from subarachnoid haemorrhage. ${ }^{10}$ Involvement of other arteries has been reported, including the coronary arteries ${ }^{11}$ and the abdominal aorta. ${ }^{12} 13$

Most of the vascular anomalies in Marfan's syndrome are proximal aortic and aortic valve related due to defects in fibrillin- $1^{5}$; however, there are rare reports of other arteries being affected, including popliteal, ${ }^{14}$ extracranial, ${ }^{15}$ renal, ${ }^{16}$ and superior mesenteric ${ }^{17}$ arteries.

Our patient fulfilled many but not all of the diagnostic criteria for Marfan's syndrome. However of greatest importance was that his aortic root and valve were of normal dimensions. The conjunction of Marfan's syndrome and polycystic disease has been reported only very rarely previously-the genes involved in polycystic disease are on chromosomes 16 and 4, whereas the fibrillin genes are on chromosomes 5 and 15 . Selgas $e a^{18}{ }^{18}$ and Somlo et $a l^{19}$ reported ADPKD kindreds with a very "marfanoid" vascular history of ascending aortic aneurysms and dissections and another, similar, kindred was reported more recently by Hateboer $e t$ al. ${ }^{20}$

On balance we believe that the relatively early onset of bilateral popliteal artery aneurysms in this patient was a feature more of his ADPKD, but we cannot rule out a contribution from a form-fruste of Marfan's syndrome.

Authors' affiliations

W Al-Hakim, D J A Goldsmith, Guy's and St Thomas' NHS Trust, London, UK

Correspondence to: Dr David J Goldsmith, Renal Unit, Guy's Hospital, London SE 1 9RT, UK; david.goldsmith@kcl.ac.uk

Submitted 27 December 2002

Accepted 10 January 2003

\section{REFERENCES}

1 Bradway MW, Drezner AD. Popliteal aneurysm presenting as acute thrombosis and ischemia in a middle-aged man with a history of Kawasaki disease. J Vasc Surg 1997;26:884-7.
2 Santos-Ocampo AS, Hoffman GS. Aneurysms and hypermobility in a 45-year-old woman. Cleve Clin J Med 1999:66:426-33.

3 Kurz S, Holder M, Laberke HG, et al. [Rupture of a renal artery aneurysm. Fulminant course, fatal complication of type IV Ehlers-Danlos syndrome in childhood.] Monatsschr Kinderheilkd 1992;140:624-8.

4 Alexiou C, Langley SM, Charlesworth P, et al. Aortic root replacement in patients with Marfan's syndrome: the Southampton experience. Ann Thorac Surg 2001;72:1502-7.

5 Segura AM, Luna RE, Horiba K, et al. Immunohistochemistry of matrix metalloproteinases and their inhibitors in thoracic aortic aneurysms and aortic valves of patients with Marfan's syndrome. Circulation 1998;98:11331-7.

6 Duffy ST, Colgan MP, Sultan S, et al. Popliteal aneurysms: a 10-year experience. Eur J Vasc Endovasc Surg 1998;16:218-22.

7 Locati P, Socrate AM, Costantini E, et al. Popliteal aneurysms: current management and outcome. Minerva Cardioangiol 1999;47:145-55.

8 Covic A, Mititiuc I, Goldsmith DJ, et al. [The progression factors in autosomal dominant polycystic disease.] Rev Med Chir Soc Med Nat lasi 1996;100:78-84

9 Griffin MD, Torres VE, Grande JP, et al. Vascular expression of polycystin. J Am Soc Nephrol 1997;8:616-26.

10 Schievink WI, Torres VE, Piepgras DG, et al. Saccular intracranial aneurysms in autosomal dominant polycystic kidney disease. J Am Soc Nephrol 1992;3:88-95

11 Hadimeri $\mathbf{H}$, Lamm C, Nyberg G. Coronary aneurysms in patients with autosomal dominant polycystic kidney disease. J Am Soc Nephrol 1998;9:837-41.

12 Stiasny B, Schulze BD, Graf S, et al. Vessel malformation in a patient with ADPKD: megadolichobasilar artery, abdominal aortic and iliac aneurysms. Contrib Nephrol 1995; 115:182-4.

13 Torra R, Nicolau C, Badenas C, et al. Abdominal aortic aneurysms and autosomal dominant polycystic kidney disease. J Am Soc Nephrol 1996:7:2483-6.

14 Wolfgarten B, Kruger I, Gawenda M. Rare manifestation of abdominal aortic aneurysm and popliteal aneurysm in a patient with Marfan's syndrome: a case report. Vasc Surg 2001;35:81-4.

15 Sztajzel R, Hefft S, Girardet C. Marfan's syndrome and multiple extracranial aneurysms. Cerebrovasc Dis 2001;11:346-9.

16 Baum MA, Harris HW Jr, Burrows PE, et al. Renovascular hypertension in Marfan syndrome. Pediatr Nephrol 1997:11:499-501.

17 Goffi L, Chan R, Boccoli G, et al. Aneurysm of a jejunal branch of the superior mesenteric artery in a patient with Marfan's syndrome. J Cardiovasc Surg (Torino) 2000;41:321-3

18 Selgas R, Temes JL, Sobrino JA, et al. [Polycystic renal disease in the adult associated with an incomplete form of Marfan's syndrome (author's transl).] Med Clin (Barc) 1981;76:311-3.

19 Somlo S, Rutecki G, Giuffra LA, et al. A kindred exhibiting cosegregation of an overlap connective tissue disorder and the chromosome 16 linked form of autosomal dominant polycystic kidney disease. J Am Soc Nephrol 1993;4:1371-8.

20 Hateboer N, Buchalter M, Davies SJ, et al. Co-occurrence of autosomal dominant polycystic kidney disease and Marfan syndrome in a kindred. Am J Kidney Dis 2000;35:753-60. 